\title{
Association of milking interval and milk production rate in an automatic milking system
}

\author{
J. F. Penry, ${ }^{* 1}$ P. M. Crump, ${ }^{*}$ L. L. Hernandez, ${ }^{*}$ and D. J. Reinemann† \\ *Department of Dairy Science, and \\ †Department of Biological Systems Engineering, University of Wisconsin, Madison 53706
}

\section{ABSTRACT}

The primary aim of this research was to describe the association between milking interval (MI) and milk production rate (MPR) at the quarter level in a large commercial farm using an automatic milking system. A secondary aim was to determine whether a 2 -h decrease in MI would increase MPR at the cow level in midlactation multiparous cows. Six months of data from 1,280 cows were used to assess the association between MI (h) and quarter MPR $(\mathrm{kg} / \mathrm{h})$. Increasing MI was associated with decreased MPR for early, mid, and late lactation, both primiparous and multiparous cows, and all 4 quarter positions and across time. The decrease in MPR is approximately $2 \% / \mathrm{h}$ of increasing $\mathrm{MI}$ for multiparous cows and $1.5 \% / \mathrm{h}$ for primiparous cows. Regardless of quarter, multiparous cows had a greater MPR than primiparous cows, and rear quarters had greater MPR than front quarters. An experiment to test the causal relationship between changing MI and cow-level MPR was conducted using 26 animal pairs matched on MI, days in milk, and milk yield. During the 21-d treatment period, the average MI of treatment cows was decreased by $2.4 \mathrm{~h}$ compared with control cows. In both the 21 - $\mathrm{d}$ treatment and 42-d posttreatment periods, no significant difference was found in cow-level MPR between the treatment and control groups. Despite the negative association between increasing MI and MPR being consistent across all assessed days in milk windows and all quarters, results from this experiment suggest that intervention to decrease MI might require an MI change greater than $2 \mathrm{~h}$ or be applied in early lactation to significantly increase MPR.

Key words: voluntary milking system, milking frequency, milk production rate

Received October 24, 2016.

Accepted September 22, 2017.

${ }^{1}$ Corresponding author: penry@wisc.edu

\section{INTRODUCTION}

Research on the association between milking frequency and milk production has appeared in the literature over several decades. Although they are related measures, milking frequency has usually been used to describe a fixed number of milkings per day (e.g., twice daily, 3 times daily), whereas milking interval (MI) is more commonly applied to define the time (h) between milkings for voluntary milking systems in which the milking frequency and MI may vary from day to day. Early research by Elliott (1961), using a half-udder design, demonstrated a $12 \%$ increase in milk yield when 3 -times-daily milking was compared with twice-daily milking - a 4-h decrease in MI. The increase in yield was noted after $1 \mathrm{~d}$ and persisted during the entire period that the 3-times-daily treatment was applied. Nørgaard et al. (2005) milked cows 3 times per day or twice daily for $8 \mathrm{wk}$ and found an increase in milk yield of $11 \%$ in the 3-times-daily group but no persistency of response from wk 11 to 16 . In an experiment conducted with mid-lactation cows comparing 3-times-daily with once-daily milking, after $8 \mathrm{wk}$ of comparison, the yield of milk harvested once daily was $40 \%$ that of milk harvested 3 times per day (Bernier-Dodier et al., 2010). Four-times-daily milking has also been compared with twice-daily milking in an experiment conducted on 4 commercial farms; the average daily increase in milk yield associated with the 4-times-daily treatment was $2.2 \mathrm{~kg} /$ cow per day, or $6.8 \%$, across the 7 mo of treatment (Soberon et al., 2011). Six-times-daily milking during the first 6 wk of lactation has been compared with 3-times-daily milking, with a significant increase in milk yield observed for the 6-times-daily treatment in addition to a carryover effect through wk 7 to 18 of lactation after the treatment had ceased (Bar-Peled et al., 1995). Hale et al. (2003) noted results similar to those of previous milking frequency experiments in an experiment comparing 4-times-daily and twicedaily milking using uneven MI. A review by Wall and McFadden (2012) concluded that a 4-h decrease in MI (twice-daily to 3 -times-daily milking) results in a 15 to $20 \%$ increase in milk yield, whereas a further $2-\mathrm{h}$ 
decrease in MI (3-times-daily to 4-times-daily milking) results in a further $7 \%$ increase in milk yield.

The studies mentioned thus far have all been based around conventional milking systems with regimented MI. The automatic milking system (AMS), or milking robot, was first introduced commercially in 1992, and there are now approximately 38,000 individual AMS units worldwide (Hallén-Sandgren and Emanuelson, 2017). Irrespective of the animal traffic design, AMS systems rely to some degree on voluntary cow movement, and MI is influenced by individual cow behavior. As such, AMS has offered new research opportunities in terms of how MI is associated with milk yield. Increasing MI in AMS has been associated with decreasing milk production per hour, with the effect of MI being greatest at higher production levels (Ouweltjes, 1998; Hogeveen et al., 2001). Daily or weekly milk yield was reported to have decreased linearly as MI increased (Bach and Busto, 2005; André et al., 2010), whereas daily milk yield was found to be negatively correlated with MI and correlated in both positive and negative directions, depending on days to peak production, with DIM (Helmreich et al., 2014). Pettersson et al. (2011) determined that high milking frequency (low MI) in early lactation was associated with an increased peak milk yield, and high milking frequency across the entire lactation was associated with an increased peak milk yield in multiparous cows milked using AMS. In addition, there was improved persistency of lactation.

Little experimental work has been conducted using AMS stocking rates typical of commercial farms (Jacobs and Siegford, 2012), and research has predominantly reported milk yield results at the udder rather than quarter level. No experiments to establish a cause-effect relationship between changes in MI and resulting production response in mid-lactation cows in AMS have been reported. The primary aim of this research was to describe the association between MI and milk production rate (MPR; $\mathrm{kg}$ of milk produced/h of MI) at the quarter level in a large commercial AMS (5 or more units in a single commercial farm). A secondary aim was to determine whether a 2- to 3-h decrease in MI would increase cow-level MPR in mid-lactation multiparous cows. Satisfying both aims, conceivably, can lead to useful information for the configuration of milking permission settings and milking strategies in AMS.

\section{MATERIALS AND METHODS}

An observational study and a planned experiment were conducted on a commercial dairy farm $(\mathrm{n}=1,280$ Holstein Friesian cows) using 20 AMS units (De Laval VMS, DeLaval, Tumba, Sweden) located in the north- eastern United States. This farm has used an AMS for more than $10 \mathrm{yr}$. The average lactation number of cows in the study herd was $2.3(\mathrm{SD}=1.1)$, with an average production level of $34.6(\mathrm{SD}=11.4) \mathrm{kg} / \mathrm{cow}$ per day. Cows are housed year-round and fed using a partial mixed ration system with concentrate feeding in the AMS stall. Concentrate feeding is not adjusted according to individual cow production levels. Each AMS services a pen of 55 cows, with 6 pens of primiparous cows (L1) and 14 pens of multiparous cows $(\mathbf{L} 2+)$. As animals freshen, they are allocated to evenly distribute cow DIM between pens. Less than $10 \%$ of the animals are moved to different pens in any 12 -mo period. Milking permission is granted to L1 cows if they had not been successfully milked in the previous $5 \mathrm{~h}$, whereas L2 + cows are granted milking permission if they have not been successfully milked in the previous $6 \mathrm{~h}$. No milk production parameters are used to determine milking permission. Under normal farm protocol, cows are fetched only if they have not recorded a successful milking within $24 \mathrm{~h}$ of the previous milking. Milking configuration of the AMS (system vacuum and pulsation settings) was not altered during the study period. Teat cup removal was based on a threshold of $0.2 \mathrm{~kg} /$ min applied at the quarter level.

\section{Observational Study}

Pen ID, cow ID, milking start time (date, hour, minute, second), milking duration (minute, second), incomplete milkings, quarter-level milk yield $(\mathrm{kg})$, average flow rate $(\mathrm{kg} / \mathrm{min})$, peak flow rate $(\mathrm{kg} / \mathrm{min})$, and conductivity $(\mathrm{mS} / \mathrm{cm})$ were recorded for each cow milking (Delpro, DeLaval). Days in milk were calculated for each milking based on calving date contained in a separate database. Quarter-level MPR was calculated by dividing the individual quarter milk yield by the time since the last milking (or MI) and is reported as kilograms per hour. Quarter MPR was averaged over 10-DIM periods. Two pens used a semiguided traffic system in which animals had to pass through the AMS to gain access to the partial mixed ration feeding area. Eighteen pens used a guided traffic system in which a presorting gate directed cows to either the feeding area or the AMS holding area. Pen design was uniform for all 20 pens with the exception of this single presorting gate in each of the guided traffic pens. Milking data from January to June 2015 comprising 539,548 individual cow milking records was available for observational study.

\section{Statistical Analysis for Observational Study}

All data manipulation and statistical analysis were performed using SAS 9.4 (SAS Institute Inc., Cary, 
NC). Each milking event had 1 MI, 1 cow-level MPR, and 4 quarter-level MPR records per cow. Cow-level milk yield for each milking was calculated by summing quarter milk yields. Incomplete milkings were removed from the data set as they typically resulted in little or no milk yield and near-zero MPR in one quarter (this criteria removed $13.2 \%$ of data). Milking records following incomplete milkings were retained as they typically occurred shortly after an incomplete milking and resulted in a slight underreporting of MPR. Records with MI greater than $24 \mathrm{~h}$ were removed from analysis as this generally indicated animal movement to the sick-cow group. Cow-level MPR greater than 2.7 $\mathrm{kg} / \mathrm{h}(>65 \mathrm{~kg} / \mathrm{d})$ or quarter-level MPR greater than $1.4 \mathrm{~kg} / \mathrm{h}(>33.6 \mathrm{~kg} / \mathrm{d})$ were also removed from analysis because they were considered biologically implausible and the result of a data recording error. These criteria removed $0.04 \%$ of the data available for analysis. For cows with records from 2 lactations within the analysis period, only the most recent lactation data were used; this accounted for approximately $86.7 \%$ of data being removed.

The study base used contained 295,766 individual milking records after exclusion criteria were applied to the 6 mo of available data. Because the size of the data set exceeded the capacity of SAS to run a full model on all data, the analysis was divided into 48 data subsets. These 48 analyses were conducted on 4 quarter locations, 2 seasons (January-March and April-June), and 3 DIM windows (50-80, 100-130, and 150-180 DIM). Data from MI 6 to $16 \mathrm{~h}$ for L1 and L2+ cows were used. These criteria provided at least 1,000 observations in each data subgroup. The MI was rounded to the nearest $0.5 \mathrm{~h}$; for example, if MI was between 6.51 and 7.49 it would be rounded to $7 \mathrm{~h}$. Rounding was performed on MI data to assist visual interpretation of the plots while not affecting the calculation of MPR versus MI slope coefficients (with the exception of slope SE). The mean quarter MPR was calculated and the REG procedure of SAS was used to perform a linear regression for the mean quarter MPR versus MI (rounded) for each of the 48 data blocks.

The MIXED procedure of SAS was used to estimate the effect of DIM window, lactation group, 3-mo season, and quarter plus 2-way interactions on either quarter MPR or the linear regression slope coefficient for quarter MPR versus MI $\left(\beta_{1}\right)$ :

$$
\begin{gathered}
\mathrm{Y}_{\mathrm{ijkl}}=\mu+\mathrm{DIM}_{\mathrm{i}}+\mathrm{S}_{\mathrm{j}}+\mathrm{LG}_{\mathrm{k}}+\mathrm{Q}_{\mathrm{l}}+(\mathrm{DIM} \times \mathrm{S})_{\mathrm{ij}} \\
+(\mathrm{DIM} \times \mathrm{LG})_{\mathrm{ik}}+(\mathrm{DIM} \times \mathrm{Q})_{\mathrm{il}}+(\mathrm{S} \times \mathrm{LG})_{\mathrm{jk}} \\
+(\mathrm{LG} \times \mathrm{Q})_{\mathrm{kl}}+(\mathrm{LG} \times \mathrm{Q})_{\mathrm{kl}}+\varepsilon_{\mathrm{ijk}}
\end{gathered}
$$

where $Y_{\mathrm{ijkl}}=$ dependent variable (mean quarter-level MPR or MPR vs. MI slope term; $\left.\beta_{1}\right) ; \mu=$ overall mean; $\mathrm{DIM}_{\mathrm{i}}=$ DIM window $(50-80,100-130$, or $150-180$ DIM; fixed effect; $\mathrm{i}=1,2,3) ; \mathrm{S}_{\mathrm{j}}=3$-mo season (January-March or April-June; fixed effect; $\mathrm{j}=1,2) ; \mathrm{LG}_{\mathrm{k}}=$ lactation group ( $\mathrm{L} 1$ or $\mathrm{L} 2+$; fixed effect; $\mathrm{k}=1,2$ ); $\mathrm{Q}_{1}$ = quarter (right front, left front, right rear, or left rear; fixed effect; $1=1,2,3,4)$; and $\varepsilon_{\mathrm{ijkl}}=$ residual error.

Quarter MPR and the MPR versus MI slope term were both declared continuous variables. Significance for least squares means was declared at the $P<0.05$ level.

The ANOVA procedure of SAS was used to estimate the effect of pen type (P) on MPR and MI. The following model was used:

$$
\mathrm{Y}_{\mathrm{ij}}=\mu+\mathrm{P}_{\mathrm{i}}+\varepsilon_{\mathrm{ij}},
$$

where $\mathrm{Y}_{\mathrm{ij}}=$ dependent variable $(\mathrm{MPR}$ or $\mathrm{MI}) ; \mu=$ overall mean; $\mathrm{P}_{\mathrm{i}}=$ pen type (semiguided traffic or guided traffic; fixed effect; $\mathrm{i}=1,2)$; and $\varepsilon_{\mathrm{ij}}=$ residual error.

Pen type was declared a categorical variable. Significance for calculated least squares means was declared at the $P<0.05$ level. This model was run using study base data from either January to March or April to June 2015 for pens housing L2+ cows only. The REG procedure of SAS was also used to perform linear regression analysis on mean MI versus DIM for L1 and L $2+$ cows between 10-d average intervals from 10 to 300 DIM.

\section{Planned Treatment and Control Experiment}

An experiment was designed to manipulate MI for a $21-d$ period in $\mathrm{L} 2+$ pens. The response variable was cow-level MPR. Eligibility criteria for cows enrolled in the experiment were lactation number 2 or higher, minimum 30-d average MI of $8 \mathrm{~h}$, and no movement between pens during the entire experiment. Changing the guided traffic system algorithm to increase milking permission opportunities and retrieve treatment cows to the AMS once daily was intended to reduce the MI of treatment cows by a minimum of $2 \mathrm{~h}$. Each treatment cow was paired with a control cow in the same pen based on 3 criteria: MI within $1 \mathrm{~h}$, DIM within $50 \mathrm{~d}$, and daily cow milk yield within $1 \mathrm{~kg}$. Twenty-six pairs met the eligibility and matching criteria. The number of treatment-control pairs ranged from 1 to 7 per pen. At the start of the experimental period, average daily milk production for pairs was $37.5 \mathrm{~kg}(\mathrm{SD}=3.6)$ and DIM was 175 d $(\mathrm{SD}=41)$. 
A 21-d pretreatment period ( $\mathrm{d}-21$ to 0$)$ was used to establish the matching criteria followed by a $21-\mathrm{d}$ treatment period (d 1-21) and a 42-d posttreatment period (d 22-64) to assess residual effects on MI and MPR. During this posttreatment period, all guided traffic and retrieval activities returned to the normal herd management routines. This experiment was conducted between May and July 2016 under IACUC-approved animal use protocol A005167.

\section{Statistical Models Used for Experiment Analysis}

Cow-level means for MI, MPR, and DIM were calculated for each experiment period: $\mathrm{d}-21$ to $-10, \mathrm{~d} 1$ to 11, d 1 to 21 , d 22 to 42 , and d 22 to 64 . Comparison of treatment and control group mean MI and MPR during the pretreatment period $\mathrm{d}-21$ to -10 was used for assessment of treatment and control group exchangeability. Data from the pretreatment period $\mathrm{d}-9$ to 0 were not used due to a milking event reporting issue in the AMS software.

The MIXED procedure of SAS was used to estimate the effect of treatment, cow-level mean treatment period DIM, and lactation number on mean cow MPR and MI (data as recorded and not rounded during pretreatment, treatment, or posttreatment periods). The following model was used:

$$
\mathrm{Y}_{\mathrm{ij}}=\mu+\mathrm{T}_{\mathrm{i}}+\mathrm{DIM}_{\mathrm{j}}+\mathrm{L}_{\mathrm{k}}+\varepsilon_{\mathrm{ij}},
$$

where $\mathrm{Y}_{\mathrm{ij}}=$ dependent variable (mean cow MPR or $\mathrm{MI}) ; \mu=$ overall mean; $\mathrm{T}_{\mathrm{i}}=$ treatment $(\mathrm{MI}$ modification treatment or control; fixed effect; $\mathrm{i}=1,2) ; \mathrm{DIM}_{\mathrm{j}}$ $=$ mean cow DIM (fixed effect; $\mathrm{j}=1, \ldots, 52) ; \mathrm{L}_{\mathrm{k}}=$ lactation number (fixed effect; $\mathrm{k}=1, \ldots, 5$ ); and $\varepsilon_{\mathrm{ij}}=$ residual error.

Treatment was declared a categorical variable, and mean cow DIM and lactation number were both continuous variables. Significance for least squares means was declared at the $P<0.05$ level.

\section{RESULTS}

\section{Observational Study}

The results of the quarter MPR observational analysis using model 1 are presented in Table 1. Decreased mean quarter MPR was significantly associated with increased DIM, front quarters compared with rear quarters, and L1 cows compared with L2+ cows. The main effect of season was not significant and was removed from the final model. There was no significant difference between front quarters or between rear quarters, and the model was reduced to 2 levels of quarter: front and rear. The interactions DIM $\times$ lactation group and DIM $\times$ quarter were also significant. Other interactive terms were not significant and were removed from the final model. A wider range of quarter MPR was observed for $\mathrm{L} 2+$ cows compared with $\mathrm{L} 1$ cows $(0.26 \mathrm{~kg} / \mathrm{h}$ range vs. $0.14 \mathrm{~kg} / \mathrm{h}$ range); the same trend was observed for front versus rear quarters in L2+ compared with L1 cows $(0.11 \mathrm{~kg} / \mathrm{h}$ range vs. $0.05 \mathrm{~kg} / \mathrm{h}$ range). Quarter MPR differences, which were significant as described in Table 1, ranged from $0.01 \mathrm{~kg} / \mathrm{h}$ or $0.24 \mathrm{~kg}$ over $24 \mathrm{~h}$ (2.8\% of average daily production assuming 4-quarter contribution) to $0.10 \mathrm{~kg} / \mathrm{h}$ or $2.4 \mathrm{~kg}$ over $24 \mathrm{~h}(27.7 \%$ of average daily production).

The results of quarter MPR versus MI slope term observational analysis from model 1 are presented in Table 2. The relationship between quarter-level MPR and MI was negative (decreasing MPR with increasing MI or negative slope term) and was linear for all quarters, lactation groups, and DIM windows and both seasons, and the coefficient of determination $\left(\mathbf{R}^{2}\right)$ for each linear regression was $80 \%$ or greater. The main effects of DIM window and lactation group were significant. The other main effects and all interactive terms were not significant and were removed from the final model. The quarter MPR versus MI slope term is an indication of the sensitivity of MPR on MI across lactation groups and stages of lactation. The mean quarter MPR versus MI slope was greatest in 50 to $80 \mathrm{DIM}$ and 100 to 130 DIM and in L2+ cows with a $2 \%$ reduction in $\mathrm{MPR} / \mathrm{h}$ of MI (Table 2).

There was a positive relationship between mean MI and DIM for L2+ cows (Figure 1 ), with an $\mathrm{R}^{2}$ value of 0.95. The relationship between MI and DIM was not as strong for L1 cows (Figure 2), with an $\mathrm{R}^{2}$ value of 0.04 .

Cow-level MPR and MI were also assessed by pen type (semiguided vs. guided traffic) and season (Table 3 ). The pens with semiguided traffic systems (both pens of L2+ cows) had significantly lower average MI compared with all other L2+ cow pen types with guided traffic systems installed. There was a significant increase in cow-level MPR in the semiguided groups in the second season (April-June) but not the first (January-March). The trend was for the cow MPR to be higher in the semiguided traffic pen types in both seasons, however. There was no significant increase in box use per day (fraction of each day during which the AMS box was being used) in the semiguided pens for either season (Table 3).

\section{Planned Treatment and Control Experiment}

The results from model 3 to assess exchangeability for the planned experiment are presented in Table 4 . During the pretreatment period ( $d-21$ to -11$)$, there 
Table 1. Results of model 1: main effects of DIM window, lactation group ${ }^{1}$ (LG), and quarter ${ }^{2}$ and significant interaction effects of $\mathrm{LG} \times \mathrm{DIM}$ and $\mathrm{LG} \times$ quarter on mean \pm SEM quarter milk production rate $(\mathrm{MPR})$

\begin{tabular}{|c|c|c|c|}
\hline Item & Quarter MPR (kg/h) & Quarter MPR, L1 & Quarter MPR, L2+ \\
\hline \multicolumn{4}{|l|}{ Main effect } \\
\hline \multicolumn{4}{|l|}{ LG } \\
\hline L1 & $0.33^{\mathrm{a}} \pm 0.002$ & & \\
\hline $\mathrm{L} 2+$ & $0.39^{\mathrm{b}} \pm 0.002$ & & \\
\hline \multicolumn{4}{|l|}{ Stage of lactation } \\
\hline 50-80 DIM & $0.38^{\mathrm{a}} \pm 0.003$ & & \\
\hline 100-130 DIM & $0.36^{\mathrm{b}} \pm 0.003$ & & \\
\hline 150-180 DIM & $0.35^{\mathrm{c}} \pm 0.003$ & & \\
\hline \multicolumn{4}{|l|}{ Quarter } \\
\hline Front & $0.33^{\mathrm{a}} \pm 0.003$ & & \\
\hline Rear & $0.39^{\mathrm{b}} \pm 0.003$ & & \\
\hline \multicolumn{4}{|l|}{ Interaction effect } \\
\hline \multicolumn{4}{|l|}{$\mathrm{LG} \times \mathrm{DIM}$} \\
\hline \multicolumn{4}{|l|}{ DIM 50-80 } \\
\hline DIM 100-130 & & $0.32^{\mathrm{a}} \pm 0.004$ & $0.39^{\mathrm{c}} \pm 0.004$ \\
\hline DIM 150-180 & & $0.33^{\mathrm{a}} \pm 0.004$ & $0.36^{\mathrm{b}} \pm 0.004$ \\
\hline \multicolumn{4}{|l|}{$\mathrm{LG} \times$ quarter } \\
\hline Front & & $0.31^{\mathrm{a}} \pm 0.004$ & $0.34^{\mathrm{b}} \pm 0.004$ \\
\hline Rear & & $0.34^{\mathrm{b}} \pm 0.004$ & $0.44^{\mathrm{c}} \pm 0.004$ \\
\hline
\end{tabular}

was no difference in MI or MPR between the cows assigned to treatment and control pairs, indicating exchangeability of treatment and control pairs.

The results from model 3 for the planned experiment are presented in Table 5. A significant difference in MI was found between treatment and control groups during the 21-d treatment period, with a decrease of MI of 2.4 $\mathrm{h}(\mathrm{SEM}=0.3)$ in the treatment group. This indicated successful application of the treatment as planned. No significant difference was found in cow MPR between treatment and control groups in the treatment period. The analyses of the posttreatment period were divided up into the first half (d 22-42) and the full period (d 22-64). A significant difference remained in both analysis windows for MI between treatment and control

Table 2. Results of model 1: main effects of DIM window and lactation group on quarter milk production rate versus mean \pm SEM milking interval linear regression slope $\left(\beta_{1}\right)$

\begin{tabular}{ll}
\hline Item & $\beta_{1}$ \\
\hline Stage of lactation & \\
50-80 DIM & $-9.49 \times 10^{-3 \mathrm{a}} \pm 4.0 \times 10^{-4}$ \\
100-130 DIM & $-8.78 \times 10^{-3 \mathrm{a}} \pm 4.0 \times 10^{-4}$ \\
150-180 DIM & $-7.43 \times 10^{-3 \mathrm{~b}} \pm 4.0 \times 10^{-4}$ \\
Lactation group $^{1}$ & $-7.10 \times 10^{-3 \mathrm{a}} \pm 3.0 \times 10^{-4}$ \\
L1 & $-9.97 \times 10^{-3 \mathrm{~b}} \pm 3.0 \times 10^{-4}$ \\
L2+ &
\end{tabular}

\footnotetext{
${ }^{\mathrm{a}, \mathrm{b}}$ Values within effect with different superscripts differ significantly $(P<0.05)$.

${ }^{1} \mathrm{~L} 1=$ primiparous cows; $\mathrm{L} 2+=$ multiparous cows.
}

groups, but there was no significant difference for cowlevel MPR.

\section{DISCUSSION}

The association between MI and milk yield in AMS using daily milk yield per cow has been reported previously (Bach and Busto, 2005; André et al., 2010; Løvendahl and Chagunda, 2011; Helmreich et al., 2014). The association between MI and MPR in AMS has been described by Hogeveen et al. (2001) and Speroni et al. (2006). In this study, we used the metric MPR rather than milk yield per day or per milking because of the difficulty in accurately estimating daily cow milk yield in AMS due to the variation in MI (Nielsen et al., 2010). We considered MPR a more appropriate way to measure milk production in AMS where milking is voluntary and the MI is not uniform within or across days. During this observational study and planned experiment, teat cup removal switch levels were not changed. We therefore assumed that the amount of milk remaining in the quarter or udder was comparable from one milking to the next and that the MPR calculation was accurate.

In the study herd, the number of animals per AMS is within the stocking rate range of 50 to 70 cows per AMS reported by Hallén-Sandgren and Emanuelson (2017) but at the lower end as the result of management decisions emphasizing cow comfort and access to feeding areas to improve daily milk yield. Because 


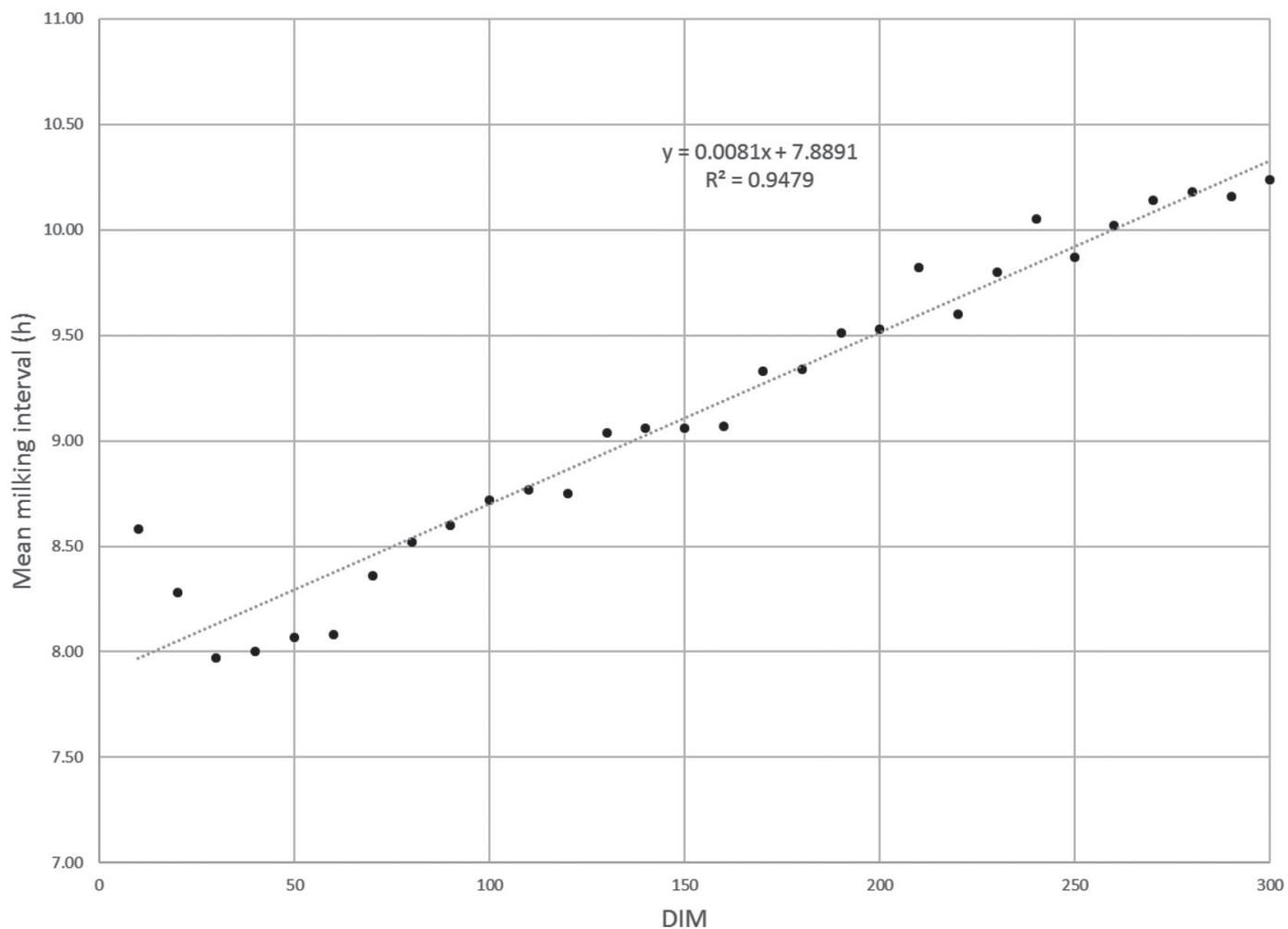

Figure 1. Results of linear regression of mean milking interval versus DIM for cows in lactation 2 to 6, January to June 2015.

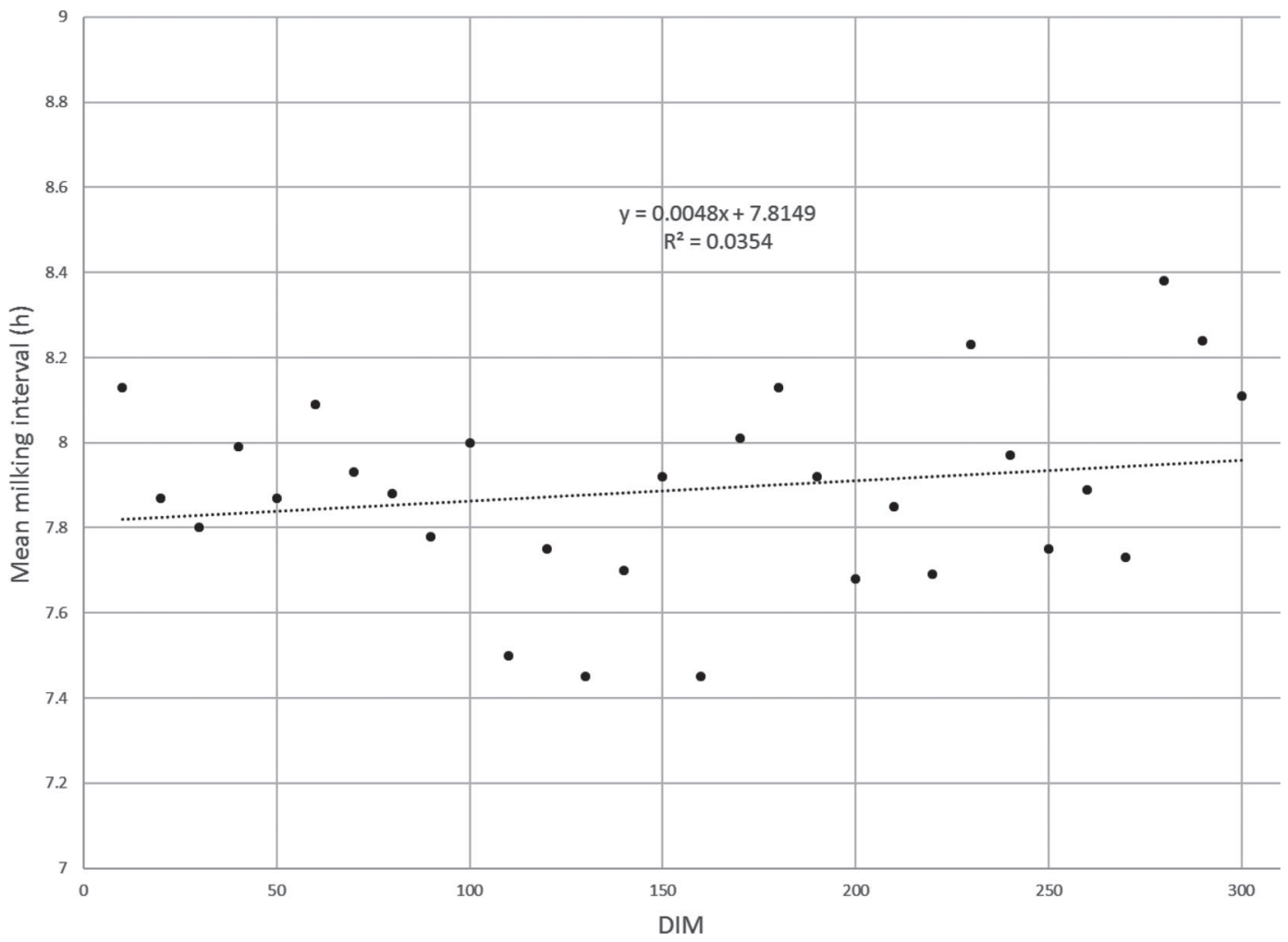

Figure 2. Results of linear regression of mean milking interval versus DIM for cows in lactation 1, January to June 2015. 
Table 3. Results of model 2: milking interval, cow milk production rate, and box use per day ${ }^{1}\left( \pm\right.$ SEM) for 2 seasons in guided traffic pens ${ }^{2}$ $(\mathrm{n}=14)$ and semiguided traffic pens ${ }^{3}(\mathrm{n}=2)$ containing multiparous cows

\begin{tabular}{lcc}
\hline Item & January-March & April-June \\
\hline Milking interval $(\mathrm{h})$ & & \\
$\quad$ Guided traffic pens & $9.8^{\mathrm{a}} \pm 0.1$ & $9.5^{\mathrm{a}} \pm 0.1$ \\
$\quad$ Semiguided traffic pens & $9.4^{\mathrm{b}} \pm 0.2$ & $8.6^{\mathrm{b}} \pm 0.2$ \\
Milk production rate $(\mathrm{kg} / \mathrm{h})$ & & \\
$\quad$ Guided traffic pens & $1.47^{\mathrm{a}} \pm 0.01$ & $1.41^{\mathrm{a}} \pm 0.01$ \\
$\quad$ Semiguided traffic pens & $1.54^{\mathrm{a}} \pm 0.03$ & $1.50^{\mathrm{b}} \pm 0.04$ \\
Box use (fraction/24 h) & & \\
$\quad$ Guided traffic pens & $0.71^{\mathrm{a}} \pm 0.01$ & $0.68^{\mathrm{a}} \pm 0.01$ \\
Semiguided traffic pens & $0.72^{\mathrm{a}} \pm 0.01$ & $0.70^{\mathrm{a}} \pm 0.01$ \\
\hline
\end{tabular}

${ }^{\mathrm{a}, \mathrm{b}}$ Values within a column and response variable (milking interval, milk production rate, and box use) with different superscripts differ significantly $(P<0.05)$.

${ }^{1}$ Box use per day is the fraction of each 24 -h period that the robotic milking box is performing an act associated with milking (preattachment preparation, milking, postmilking disinfection).

${ }^{2}$ Guided traffic pens use a sorting gate to direct cows to either a holding area ahead of the automatic milking system box holding area or the feeding location based on milking permission criteria.

${ }^{3}$ In semiguided traffic pens, all cows enter the holding area ahead of the automatic milking system box and are milked or released to the feeding area based on milking permission criteria.

stocking rate is constant between all pens and pen size is standardized, the number of cows per AMS was not a variable considered for analysis. Cows in this herd are fetched only if they exceed a 24-h MI since the previous milking, and this fetching policy is not modified for DIM. As a result, it safely can be assumed that individual cows have the ability to determine their own MI between approximately 6 and $24 \mathrm{~h}$ regardless of the stage of lactation. Variation in MI is an attribute of the individual cow (Løvendahl and Chagunda, 2011), and heritability of daily milking frequency ranges from 0.02 to 0.08 (Nixon et al., 2009).

As described in Table 1, quarter MPR was significantly greater in rear quarters compared with front quarters. The lower MPR for the latter DIM period in L2+ cows (Table 1) is in general agreement with Pettersson et al. (2011), who referred to the slope of decline in milk yield with increasing DIM (DIM 100-300) as lactation persistency. The quarter MPR for both front and rear quarters across all 3 DIM windows was

Table 4. Results of model 3: mean \pm SEM milking interval (MI) and cow milk production rate (MPR) during the pretreatment period (d -21 to -11$)$

\begin{tabular}{lcc}
\hline Item & Treatment & Control \\
\hline MI $(\mathrm{h})$ & $10.7^{\mathrm{a}} \pm 0.35$ & $10.5^{\mathrm{a}} \pm 0.34$ \\
MPR $(\mathrm{kg} / \mathrm{h})$ & $1.49^{\mathrm{a}} \pm 0.06$ & $1.55^{\mathrm{a}} \pm 0.06$ \\
\hline
\end{tabular}

${ }^{a}$ Values within a row with the same superscript do not differ significantly $(P>0.05)$.
Table 5. Results of model 3: mean \pm SEM milking interval (MI) and cow milk production rate (MPR) for treatment and control groups during the treatment and posttreatment periods

\begin{tabular}{lcccc}
\hline & Treatment & & \multicolumn{2}{c}{ Posttreatment } \\
\cline { 2 - 2 } Item & $\mathrm{d} 1-21$ & & $\mathrm{~d} 22-42$ & $\mathrm{~d} 22-64$ \\
\hline MI $(\mathrm{h})$ & & & \\
$\quad$ Treatment & $8.0^{\mathrm{a}} \pm 0.3$ & & $10.0^{\mathrm{a}} \pm 0.3$ & $10.4^{\mathrm{a}} \pm 0.3$ \\
Control & $10.4^{\mathrm{b}} \pm 0.3$ & & $11.4^{\mathrm{b}} \pm 0.3$ & $11.5^{\mathrm{b}} \pm 0.3$ \\
MPR (kg/h) & & & & \\
$\quad$ Treatment & $1.47^{\mathrm{a}} \pm 0.3$ & & $1.36^{\mathrm{a}} \pm 0.5$ & $1.30^{\mathrm{a}} \pm 0.5$ \\
Control & $1.47^{\mathrm{a}} \pm 0.3$ & & $1.33^{\mathrm{a}} \pm 0.5$ & $1.30^{\mathrm{a}} \pm 0.5$ \\
\hline $\begin{array}{l}\text { a,b } \\
\text { Values within a column and response variable with different super- }\end{array}$ \\
scripts differ significantly $(P<0.05)$.
\end{tabular}

significantly higher for L2+ cows compared with L1 cows $(0.34$ vs. $0.31 \mathrm{~kg} / \mathrm{h}$ for front quarters and 0.44 vs. $0.31 \mathrm{~kg} / \mathrm{h}$ for rear quarters; Table 1$)$. Rear-quarter MPR was greater than front-quarter MPR for both lactation groups; however, the difference was greater in L2+ cows than in L1 cows (Table 1). In a study, using a single week of AMS data from 5 farms, milk yield was found to be higher for L2+ cows compared with L1 cows (André et al., 2010), whereas Pettersson et al. (2011) determined that although L2+ cows had higher peak milk yield, there was little difference in lactation persistency between L2+ and L1 cows after analysis of 240 full lactation records from an AMS facility.

The analysis of quarter MPR versus MI, summarized in Table 2, shows that as MI increased, quarter MPR decreased across lactation number and stage of lactation for both front and rear quarters. This is in agreement with all other authors who have performed a similar analysis of the association between MI and daily milk yield (Bach and Busto, 2005; Pettersson et al., 2011; Helmreich et al., 2014) and between MI and MPR (Hogeveen et al., 2001). In agreement with the conclusions reached by Bach and Busto (2005) and the experimental studies reviewed by Wall and McFadden (2008), we contend that trends in MPR observed in this observational study are likely a result of altered MI and subsequent effects on mammary epithelial cell activity. Previous studies have also described a linear relationship between MI and either MPR (Speroni et al., 2006) or MI and weekly milk yield (Bach and Busto, 2005), although a nonlinear relationship between decreasing daily milk yield and increasing MI between 8 and 24 $\mathrm{h}$ has also been described (Delamaire and GuinardFlament, 2006). Any potential changes in MPR as a result of alterations in udder cistern fill between milkings cannot be assessed in this study design as it was not measured. The range of $\mathrm{R}^{2}$ values for our linear regressions was 0.80 to 0.98 , but in general the $R^{2}$ value was above 0.90 , indicating that the relationship 
between MPR and MI in our data was described well by a linear trend.

From 30 to 300 DIM, the average MI increases from approximately 8 to $10.2 \mathrm{~h}$ for L $2+$ cows. The $\mathrm{R}^{2}$ for this regression is high at 0.95 . Conversely, no meaningful trend was observed for average MI and DIM in the L1 group, with the average MI remaining between 7.8 and $8 \mathrm{~h}$ (Figure 2; note the difference in MI scales in Figures 1 and 2). The increase in MI with increasing DIM in $\mathrm{L} 2+$ cows is in general agreement with a previous study that described average MI for 3 stages of lactation: 8.2 h (early), $9.6 \mathrm{~h}$ (mid), and $11.1 \mathrm{~h}$ (late; Dzidic et al., 2004). Løvendahl and Chagunda (2011) also observed a declining MI with increasing DIM after or before 2 mo, but in this study L1 and L2+ animals were housed together. Regarding the difference between $\mathrm{L} 2+$ and L1 cows, both Speroni et al. (2006) and Pettersson et al. (2011) also observed a smaller increase in MI with increasing DIM in L1 cows than in L2+ cows.

The results from the observational study of MI and quarter MPR showed an association between an increase of approximately $2 \%$ in quarter MPR for each 1-h decrease in MI. This led us to hypothesize that manipulating MI by a relatively small amount $(2 \mathrm{~h})$ could influence quarter- and cow-level MPR. Previous experiments comparing a shift from twice-daily to 3-times-daily milking or twice-daily to once-daily milking with mid-lactation cows (around 169 DIM) showed a significant milk production response (Bernier-Dodier et al., 2010). In our study herd, data on the variance of observed MPR were used in an experiment power calculation with an $\alpha$ of 0.05 and a $\beta$ of 0.80 for a paired experimental design, indicating that 10 cow pairs would be required to detect a $0.04 \mathrm{~kg} / \mathrm{h}$ change in quarter MPR. This was the hypothesized change in MPR if MI could be decreased by $1.5 \mathrm{~h}$. In the experiment, 26 cow pairs were used to provide increased study power. A post hoc power calculation indicates that a change in quarter MPR of $0.03 \mathrm{~kg} / \mathrm{h}$ (or an approximate cow MPR of $0.12 \mathrm{~kg} / \mathrm{h}$ ) could have been detected with this experimental design.

Throughout the treatment and posttreatment periods described in Table 5, there was a significant decrease in MI for the treatment animals. During the treatment period (d 1-21), the decrease in MI $(\sim 2.4 \mathrm{~h}$; SEM = $0.3)$ was larger than the decrease of $1.5 \mathrm{~h}$ in the experimental design and indicates that the planned treatment was applied successfully. A significant decrease in MI persisted into the entire posttreatment period $(\mathrm{d}$ 22-64). It has been postulated that cows develop an individual and consistent feeding and drinking pattern in an AMS facility (Melin et al., 2005), and hence it was presumed in this postexperiment period that treatment cows would return to an MI similar to that measured in the pretreatment period $(\mathrm{d}-21$ to -10$)$. Although it has been observed that human activity around the AMS will increase cow activity in the vicinity of the AMS box (Wagner-Storch and Palmer, 2003), cow retrieval procedures had resumed pre-experiment levels during the posttreatment period (d 22-64).

During the treatment period (d 1-21) and the posttreatment period (d 22-64), no significant difference in cow-level MPR was detected between treatment and control cows. In a half-udder design conducted during the mid-lactation period, Bernier-Dodier et al. (2010) measured increased milk yield of approximately $2 \mathrm{~kg} / \mathrm{d}$ when contralateral quarters increased milking frequency from twice daily to 3 times daily, but in this instance the MI was decreased by $4 \mathrm{~h}$. Similarly, Wall and McFadden (2008), also in a half-udder experiment, observed a significant increase in milk yield when MI was decreased from $12 \mathrm{~h}$ to $6 \mathrm{~h}$. There are no reports in the literature of MI being manipulated by $2 \mathrm{~h}$ in AMS, but an experiment that decreased MI by $3.7 \mathrm{~h}$ in one cow group demonstrated a maintenance of milk yield during the mid-lactation period in contrast to a second group that was observed with an increasing MI during the same period (Melin et al., 2005). Increases in milk yield with decreasing MI have been observed within $2 \mathrm{~d}$ of MI being altered, but again, the decrease in MI was greater than $4 \mathrm{~h}$ (Linnerud et al., 1966). The association between MI and MPR was not validated as a cause-effect relationship in our study. The decrease in MI applied in this experiment might not have been sufficient to trigger the local autocrine and paracrine factors known to be at least partially responsible for increased milk production (Weaver and Hernandez, 2016). The variation in milk yield explained by MI, when compared with other factors such as parity, DIM, herd season, production level, and cow, is relatively low (Ouweltjes, 1998), and a constant MPR up to an MI of $12 \mathrm{~h}$ has been reported (Knight et al., 1994). Based on our experimental results, we can infer no MPR increases in mid-lactation cows from herd management strategies designed to reduce MI despite our observational study results suggesting that MPR increases may have been possible through altered cow traffic in the AMS. Further research using AMS investigating the potential causal relationship between relatively small decreases in MI and change in MPR in early lactation may be indicated as a result of our findings.

Results from this experiment indicating no significant change in cow MPR lead us to more closely examine MI and cow MPR analyzed by pen type. Milk production per AMS unit from a 6-mo period (January to June 2015; not reported) had shown increased milk 
yield from the 2 pen types where semiguided traffic, rather than guided traffic, was used. The study herd owners had modified only 2 pens to semiguided traffic as part of a small-scale farm-based assessment of traffic systems. Semiguided traffic allows cows access to the feeding area via the AMS without having to first pass through a sorting gate, which would then determine cow traffic to the feeding area or, alternatively, the AMS. The MI observed for both the guided and semiguided traffic pens (Table 3) are in general agreement with the MI reported in other trials involving AMS: $8.9 \mathrm{~h}$ (Castro et al., 2012), $9.2 \mathrm{~h}$ (de Koning and Ouweltjes, 2000), $9.6 \mathrm{~h}$ (Dzidic et al., 2004), and $9.2 \mathrm{~h}$ (Hogeveen et al., 2001). For each 3-mo season assessed, the MI of the semiguided traffic pens is significantly lower than that of the guided traffic pens, with the difference ranging from 0.4 to $0.9 \mathrm{~h}$. Two studies have reported similar findings, with lower MI associated with free traffic pens (Helmreich et al., 2014; Tremblay et al., 2016). Conversely, Hermans et al. (2003) observed no difference in milking frequency between 2 herds using guided traffic compared with 2 semiforced herds, but in the guided-traffic herds the AMS was visited more often for nonmilking visits. In that study, semiforced herds had access to feed without requiring passage through the AMS. A Danish study reported a 0.6-h increase in MI for a free-traffic herd compared with a guided-traffic herd (Friggens and Rasmussen, 2001). The range of milking box use per day observed in this study (0.67-0.75; Table 3) is appreciably lower than the optimal of $90 \%$ claimed by Castro et al. (2012) or a target occupancy rate, being the same metric, of 0.80 (de Koning and Ouweltjes, 2000). Although not reported in the results, the standard deviation of MI in our study was between 2.8 and $3.5 \mathrm{~h}$, which aligns with that published by Hogeveen et al. (2001), who also observed that MI has considerable variability between cows. A high degree of individual cow variability in milking frequency was highlighted in a recently published review on AMS (Jacobs and Siegford, 2012).

\section{CONCLUSIONS}

A 6-mo observational study showed an association between increasing $\mathrm{MI}$ and decreasing quarter-level MPR. In general, quarter MPR for any given MI was higher for L2+ cows compared with L1 cows and for rear quarters compared with front quarters. However, in a controlled experiment in which we decreased MI by $2.4 \mathrm{~h}$, we did not observe a change in cow-level MPR in mid-lactation L2+ cows. Management strategies to manipulate MI, and hence alter MPR, might require a decrease of greater than $2 \mathrm{~h}$ or an intervention period in early lactation.

\section{ACKNOWLEDGMENTS}

This research, conducted by the University of Wisconsin-Madison, is supported by Avon Dairy Solutions (Melksham, UK) and Dairy Australia (Melbourne). The researchers express their gratitude to the owners and staff at Mason Dixon Dairies (Gettysburg, PA) for their assistance with this study.

\section{REFERENCES}

André, G., P. B. M. Berentsen, B. Engel, C. de Koning, and A. Lansink. 2010. Increasing the revenues from automatic milking by using individual variation in milking characteristics. J. Dairy Sci. 93:942-953.

Bach, A., and I. Busto. 2005. Effects on milk yield of milking interval regularity and teat cup attachment failures with robotic milking systems. J. Dairy Res. 72:101-106.

Bar-Peled, U., E. Maltz, I. Bruckental, Y. Folman, Y. Kali, H. Gacitua, A. R. Lehrer, C. H. Knight, B. Robinzon, H. Voet, and H. Tagari. 1995. Relationship between frequent milking or suckling in early lactation and milk production of high producing dairy cows. J. Dairy Sci. 78:2726-2736.

Bernier-Dodier, P., L. Delbecchi, G. F. Wagner, B. G. Talbot, and P. Lacasse. 2010. Effect of milking frequency on lactation persistency and mammary gland remodeling in mid-lactation cows. J. Dairy Sci. 93:555-564.

Castro, A., J. M. Pereira, C. Amiama, and J. Bueno. 2012. Estimating efficiency in automatic milking systems. J. Dairy Sci. 95:929-936.

de Koning, K., and W. Ouweltjes. 2000. Maximising the milking capacity of an automatic milking system. Pages 38-46 in Robotic Milking. H. Hogeveen and A. Meijering, ed. Wageningen Academic Publishers, Wageningen, the Netherlands.

Delamaire, E., and J. Guinard-Flament. 2006. Longer milking intervals alter mammary epithelial permeability and the udder's ability to extract nutrients. J. Dairy Sci. 89:2007-2016.

Dzidic, A., D. Weiss, and R. M. Bruckmaier. 2004. Oxytocin release, milk ejection and milking characteristics in a single stall automatic milking system. Livest. Prod. Sci. 86:61-68.

Elliott, G. M. 1961. The effect on milk yield of three times a day milking and of increasing the level of residual milk. J. Dairy Res. 28:209-219.

Friggens, N. C., and M. D. Rasmussen. 2001. Milk quality assessment in automatic milking systems: Accounting for the effects of variable intervals between milkings on milk composition. Livest. Prod. Sci. 73:45-54.

Hale, S. A., A. V. Capuco, and R. A. Erdman. 2003. Milk yield and mammary growth effects due to increased milking frequency during early lactation. J. Dairy Sci. 86:2061-2071.

Hallén-Sandgren, C., and U. Emanuelson. 2017. Is there an ideal automatic milking system cow and is she different from an ideal parlormilked cow? Pages 61-68 in Proc. 56th Natl. Mastitis Counc. Ann. Mtg., St. Pete Beach, FL. Natl. Mastitis Counc. Inc., New Prague, MN.

Helmreich, S., R. Hauser, T. Jungbluth, B. Wechsler, and L. Gygax. 2014. Time-budget constraints for cows with high milking frequency on farms with automatic milking systems. Livest. Sci. 167:315-322.

Hermans, G. G. N., A. H. Ipema, J. Stefanowska, and J. H. M. Metz. 2003. The effect of two traffic situations on the behavior and performance of cows in an automatic milking system. J. Dairy Sci. $86: 1997-2004$.

Hogeveen, H., W. Ouweltjes, C. de Koning, and K. Stelwagen. 2001. Milking interval, milk production and milk flow-rate in an automatic milking system. Livest. Prod. Sci. 72:157-167.

Jacobs, J. A., and J. M. Siegford. 2012. Invited review: The impact of automatic milking systems on dairy cow management, behavior, health, and welfare. J. Dairy Sci. 95:2227-2247. 
Knight, C. H., D. Hirst, and R. J. Dewhurst. 1994. Milk accumulation and distribution in the bovine udder during the interval between milkings. J. Dairy Res. 61:167-177.

Linnerud, A. C., E. V. Caruolo, G. E. Miller, G. D. Marx, and J. D. Donker. 1966. Lactation studies. X. Total daily production as affected by number of times milked, number of times stimulated, and method of stimulation. J. Dairy Sci. 49:1529-1532.

Løvendahl, P., and M. G. G. Chagunda. 2011. Covariance among milking frequency, milk yield, and milk composition from automatically milked cows. J. Dairy Sci. 94:5381-5392.

Melin, M., K. Svennersten-Sjaunja, and H. Wiktorsson. 2005. Feeding patterns and performance of cows in controlled cow traffic in automatic milking systems. J. Dairy Sci. 88:3913-3922.

Nielsen, P. P., G. Pettersson, K. M. Svennersten-Sjaunja, and L. Norell. 2010. Technical note: Variation in daily milk yield calculations for dairy cows milked in an automatic milking system. J. Dairy Sci. 93:1069-1073.

Nixon, M., J. Bohmanova, J. Jamrozik, L. R. Schaeffer, K. Hand, and F. Miglior. 2009. Genetic parameters of milking frequency and milk production traits in Canadian Holsteins milked by an automated milking system. J. Dairy Sci. 92:3422-3430.

Nørgaard, J., A. Sorensen, M. T. Sorensen, J. B. Andersen, and K. Sejrsen. 2005. Mammary cell turnover and enzyme activity in dairy cows: Effects of milking frequency and diet energy density. J. Dairy Sci. 88:975-982.

Ouweltjes, W. 1998. The relationship between milk yield and milking interval in dairy cows. Livest. Prod. Sci. 56:193-201.
Pettersson, G., K. Svennersten-Sjaunja, and C. H. Knight. 2011. Relationships between milking frequency, lactation persistency and milk yield in Swedish Red heifers and cows milked in a voluntary attendance automatic milking system. J. Dairy Res. 78:379-384.

Soberon, F., C. M. Ryan, D. V. Nydam, D. M. Galton, and T. R. Overton. 2011. The effects of increased milking frequency during early lactation on milk yield and milk composition on commercial dairy farms. J. Dairy Sci. 94:4398-4405.

Speroni, M., G. Pirlo, and S. Lolli. 2006. Effect of automatic milking systems on milk yield in a hot environment. J. Dairy Sci. 89:4687-4693.

Tremblay, M., J. P. Hess, B. M. Christenson, K. K. McIntyre, B. Smink, A. J. van der Kamp, L. G. de Jong, and D. Dopfer. 2016. Factors associated with increased milk production for automatic milking systems. J. Dairy Sci. 99:3824-3837.

Wagner-Storch, A. M., and R. W. Palmer. 2003. Feeding behavior, milking behavior, and milk yields of cows milked in a parlor versus an automatic milking system. J. Dairy Sci. 86:1494-1502.

Wall, E. H., and T. B. McFadden. 2008. Use it or lose it: Enhancing milk production efficiency by frequent milking of dairy cows. J. Anim. Sci. 86:27-36.

Wall, E. H., and T. B. McFadden. 2012. Triennial Lactation Symposium: A local affair: How the mammary gland adapts to changes in milking frequency. J. Anim. Sci. 90:1695-1707.

Weaver, S. R., and L. L. Hernandez. 2016. Autocrine-paracrine regulation of the mammary gland. J. Dairy Sci. 99:842-853. 